
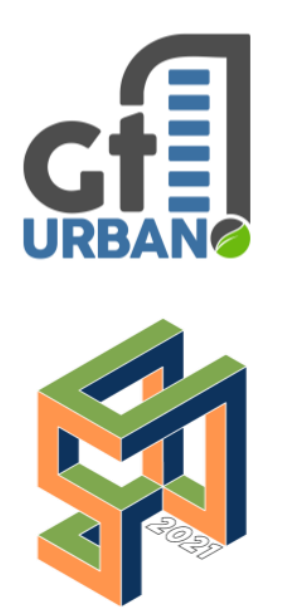

SINGEURB

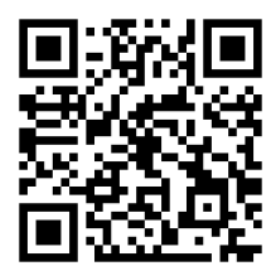

Como citar:

RODRIGUES, Rafael

Felipe Teixeira; CHARLES, Mariana Ribeiro; ALVES, Rosane Martins. Análise da concentração de Covid19 em efluentes na região metropolitana do Rio de Janeiro como ferramenta de gestão de saneamento e saúde. In: III SIMPÓSIO NACIONAL DE GESTÃO E ENGENHARIA URBANA: SINGEURB, 2021, Maceió. Anais... Porto Alegre: ANTAC, 2021. p. 209-2017.

Disponível em: https://eventos.antac.or g.br/index.php/singeurb /issue/view/14

\title{
Análise da concentração de Covid-19 em efluentes na região metropolitana do Rio de Janeiro como ferramenta de gestão de saneamento e saúde Analysis of Covid-19 effluents concentration on Rio de Janeiro metropolitan region as amanagement sanitation and health tool
}

Rafael Felipe Teixeira Rodrigues, Universidade Federal do Rio de Janeiro, rafaelftr@poli.ufrj.br

Mariana Ribeiro Charles, Universidade Federal do Rio de Janeiro, marianacharles@poli.ufrj.br

Rosane Martins Alves, Universidade Federal do Rio de Janeiro, rosane.alves@poli.ufrj.br

\section{RESUMO}

O saneamento básico pode ser considerado um aliado do sistema de saúde em duas frentes principais. Inicialmente, por não permitir o contato da população com os efluentes domésticos, diminuindo a proliferação de doenças e, desta forma, desafogando o sistema de saúde. Por outro lado, viabiliza a avaliação qualitativa e quantitativa dos patógenos presentes no esgoto coletado, permitindo a otimização das ações e investimentos em saúde pública. No presente artigo, o tema de saneamento é abordado a partir de sua relação direta com a saúde pública, especialmente ligado ao controle epidemiológico, visando demonstrar a aplicabilidade do monitoramento de efluentes como ferramenta de gestão de saneamento e saúde pública. Trata-se de um trabalho desenvolvido no curso de Mestrado, onde serão apresentados resultados parciais sobre dois estudos realizados com este monitoramento. A partir da análise do tema, é possível estimar a importância do monitoramento dos efluentes domésticos, com uso de indicadores para que o sistema de saúde possa, além de tratar doenças, prevenir surtos e até controlar a propagação de epidemias. Este artigo contribui para reforçar a urgência da universalização do saneamento e a sua importância na gestão pública de saúde.

Palavras-chave: Saneamento básico, COVID-19, Saúde Pública.

\section{ABSTRACT \\ Basic sanitation can be considered an ally of the health system in two ways. Initially, because it does not allow the population to come into contact with domestic effluents, reducing the proliferation of diseases and, in this way, relieving the health system. On the other hand, it enables the qualitative and quantitative assessment of pathogens present in collected sewage, allowing the optimization of actions and investments in public health. In this article, the}


sewage treatment is approached from its direct relation with public health, especially linked to epidemiological control, aiming to demonstrate the applicability of monitoring household effluents as a tool for managing sanitation and public health. This is a work developed in the master's degree, where partial results of two studies carried out with this monitoring will be presented. From the analysis of the topic, it is possible to estimate the importance of monitoring domestic effluents, with the use of indicators so that the health system can, in addition to treating diseases, prevent outbreaks and even control the spread of an epidemic. This article contributes to reinforce the urgency of universal sanitation and its importance in public health management.

Keywords: Basic Sanitation, COVID-19, Public Health.

\section{INTRODUÇÃO}

A relação direta entre saneamento e saúde não se aplica apenas no cotidiano atual. Segundo Teixeira, Gomes e Souza (2011), há registros com mais de 4 mil anos de civilizações que dispunham de sistemas de drenagem de águas pluviais e até coleta de esgoto sanitário. Rosen (1994) cita que já na civilização creto-micênica havia a preocupação com a destinação de dejetos e que os romanos detinham conhecimentos sobre a engenharia sanitária. Esta relação se consolida a partir da análise de estudos já realizados, que permitem concluir que quanto maior é a cobertura de saneamento no país, melhores são os indicadores de saúde pública (HELLER, 1997).

Pode-se dizer que a promoção de um ambiente salubre passa pelo abastecimento de água potável, drenagem de águas pluviais, coleta e tratamento de esgotos, além do manejo de resíduos sólidos. Segundo Ribeiro e Rook (2010), dados divulgados pelo Ministério da Saúde estimam que para cada $R \$ 1,00$ investido em saneamento, economiza-se $\mathrm{R} \$ 4,00$ em custos de atendimento na saúde pública. O Instituto Trata Brasil (2007) alerta que mesmo sendo uma questão do século passado, a estimativa é de que a universalização do acesso à rede de esgotos só se dará em 115 anos, sendo que hoje, mais da metade da população brasileira vive sem saneamento. A Organização Mundial da Saúde (OMS) estima que, todos os anos, aproximadamente 15 mil brasileiros morrem e outros 350 mil procuram o sistema de saúde com doenças ligadas à precariedade do saneamento básico (OAB NACIONAL, 2020).

Em 2020, foi sancionado o Novo Marco Legal do Saneamento, Lei Federal no 14.026/2020, em uma tentativa de, por meio da regulamentação, incentivar investimentos privados no setor que, atualmente, é majoritariamente financiado com recursos públicos, de forma a viabilizar a universalização do acesso ao saneamento básico. Nesse contexto, surge a possibilidade da utilização de ferramentas de monitoramento de esgotos urbanos visando auxiliar o enfrentamento a uma pandemia, em meio a uma crise sanitária, partindo da premissa de uma relação direta entre saneamento básico e saúde pública.

\section{CENÁRIO ATUAL DE SANEAMENTO E O MONITORAMENTO DE EFLUENTES COMO FERRAMENTA DE GESTÃO}

A viabilidade da utilização da análise de efluentes como caracterização da população local com o intuito de promover políticas públicas, em especial de saúde, depende, diretamente, do acesso ao saneamento. Para um monitoramento eficiente, é preciso garantir a equidade social no que tange à coleta de esgoto sanitário, isto é, possibilitar que todos igualmente tenham acesso à rede coletora. 
Segundo o Instituto Trata Brasil (2021), para a universalização do acesso ao saneamento, tem-se $\mathrm{R} \$ 113,30$ como investimento médio necessário por habitante. Nas 20 melhores cidades brasileiras do Ranking do Saneamento, houve um investimento, entre 2015 a 2019, de R\$84,59. Já entre as 20 piores cidades, o investimento médio anual no mesmo período ficou em $\mathrm{R} \$ 31,45$. Ou seja, nos dois pólos do Ranking o investimento médio fica abaixo, $25 \%$ e $72 \%$ respectivamente, do ideal para atingir a universalização.

\subsection{Panorama brasileiro de saneamento básico com enfoque no esgotamento sanitário}

O Instituto Trata Brasil (2021) aponta que cerca 5,5 milhões de cidadãos que vivem nas 100 maiores cidades brasileiras não têm acesso à água tratada, segundo novo Ranking do Saneamento. Os dados do estudo têm origem no Sistema Nacional de Informações sobre Saneamento (SNIS) de 2019. O mesmo documento evidencia que no primeiro ano da pandemia causada pelo Sars-Cov-2, aproximadamente 100 milhões de pessoas não tinham acesso à rede coletora de esgotos, sendo que 21,7 milhões destas, o equivalente à população do Chile, estão dentro das 100 maiores cidades do Brasil.

O Quadro 01 consolida alguns dos dados apresentados no novo Ranking do Saneamento, cabendo ressaltar que, mesmo com os maiores investimentos, estas cidades ainda apresentam sérios problemas em relação ao manejo do seu esgoto, sendo que algo próximo a $25 \%$ de seus munícipes não têm seu esgoto coletado. Destaca-se, ainda, que estes maiores municípios possuem indicadores melhores que a média nacional e que, juntos, representam 50\% de todo investimento do Brasil em infraestrutura de água e esgoto (INSTITUTO TRATA BRASIL, 2021).

Quadro 01 - Números do Ranking do Saneamento

\begin{tabular}{|c|c|}
\hline CARACTERIZAÇÃO & QUANTIDADE \\
\hline População total dos 100 maiores municípios & 85.372 .253 \\
\hline $\begin{array}{l}\text { População total atendida com abastecimento de } \\
\text { água nos } 100 \text { maiores municípios }\end{array}$ & 79.827.359 \\
\hline $\begin{array}{l}\text { População total sem acesso à água potável nos } \\
\qquad 100 \text { maiores municípios }\end{array}$ & 5.544 .894 \\
\hline $\begin{array}{l}\text { População total atendida com esgotamento } \\
\text { sanitário nos } 100 \text { maiores municípios }\end{array}$ & 63.575 .288 \\
\hline $\begin{array}{l}\text { População total sem acesso à coleta de esgoto } \\
\text { nos } 100 \text { maiores municípios }\end{array}$ & 21.796 .965 \\
\hline
\end{tabular}

Fonte: Adaptado de Instituto Trata Brasil (2021)

\subsection{O estudo Monitora Corona}

O estudo Monitora Corona realiza o monitoramento espaço-temporal da concentração de SARS-Cov-2 nos esgotos sanitários da Região Metropolitana do Rio de Janeiro - RMRJ. Foi concebido em Setembro de 2020, por meio de um contrato entre a Companhia Estadual de Águas e Esgotos (CEDAE) e a Universidade Federal do Rio de Janeiro (UFRJ), sob interveniência administrativa-financeira da Fundação COPPETEC. 
Visando apoiar políticas de vigilância e controle epidemiológico da COVID-19, o Estudo Monitora Corona realiza o monitoramento de alguns pontos estrategicamente definidos na rede de esgoto da RMRJ que é operada pela CEDAE (CEDAE et al., 2021b).

De acordo com o relatório de Abril, disponível no site do Estudo (monitoracoronarj.com.br), o monitoramento é feito em 10 pontos, abrangendo os municípios do Rio de Janeiro, Duque de Caxias, Nilópolis, São João de Meriti, Mesquita, Belford Roxo e São Gonçalo, todos dentro da RMRJ. Estes pontos são aqueles em que existe convergência dos esgotos sanitários advindos das áreas atendidas por sistemas operados e mantidos pela CEDAE e estão localizados junto à entrada de Estações de Tratamento de Esgoto (ETE) ou Estações Elevatórias de Esgoto (EEE), conforme ilustra a Figura 1.

Figura 1 - Limites dos sistemas de esgotamento sanitário e áreas urbanas potencialmente contribuintes aos respectivos pontos de monitoramento

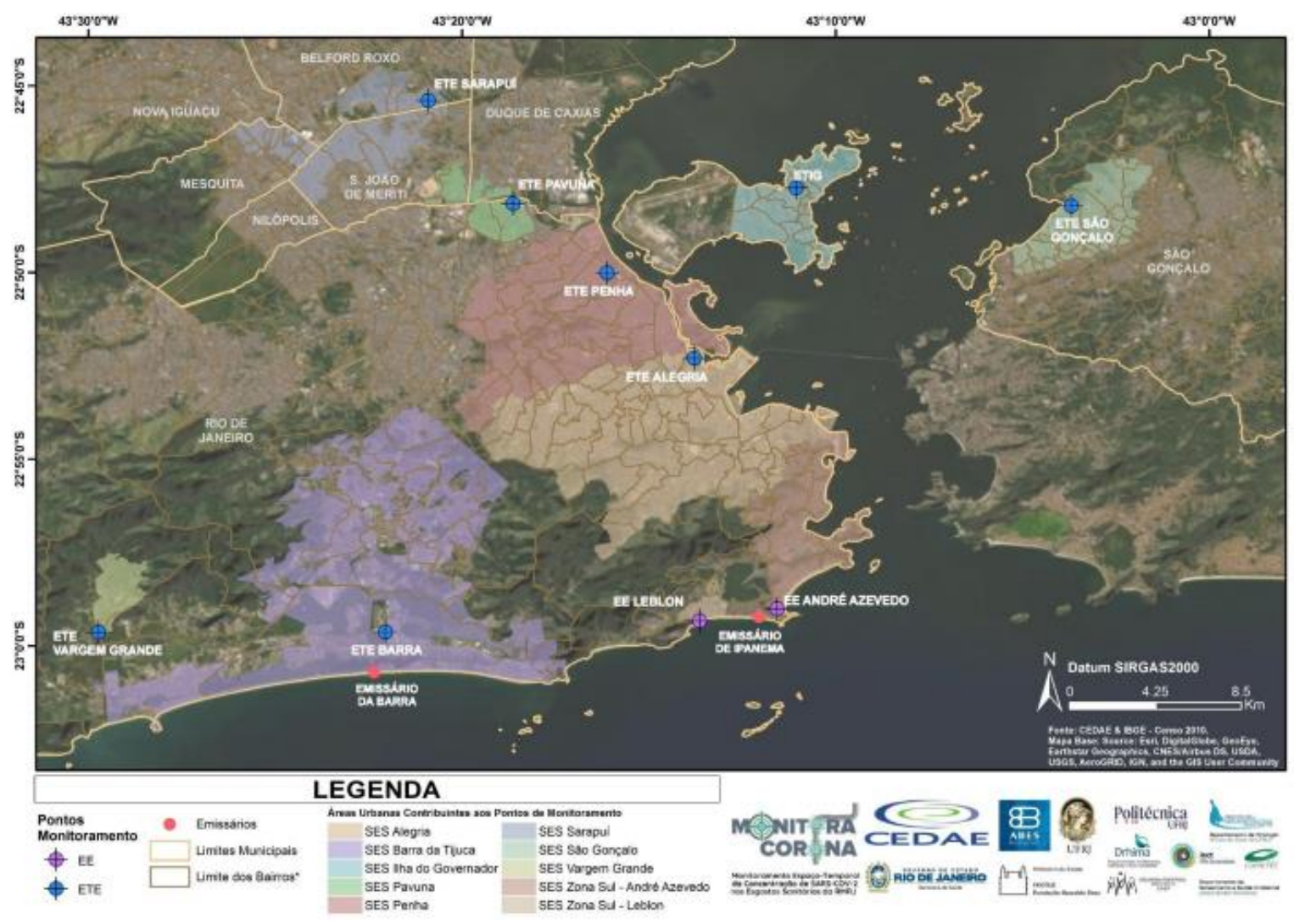

Fonte: CEDAE et al. (2021b)

As amostras coletadas semanalmente são analisadas de forma a permitir a quantificação da concentração viral nos pontos em estudo. Estas informações são relacionadas com indicadores socioeconômicos do último Censo do Instituto Brasileiro de Geografia e Estatística (IBGE), de 2010, formando uma base georeferenciada e temporal de dados.

A interpretação dos dados do monitoramento do vírus SARS-CoV-2 no esgoto ainda requer tempo de aprimoramento e observação para sua consolidação. Muito se tem a descobrir sobre a COVID-19, enquanto doença, tratamento e monitoramento. Algumas pesquisas identificaram o SARS-CoV-2 nas fezes de 
indivíduos com RT-PCR negativo. Outro ponto seria o período em que se excreta o vírus, havendo, atualmente, relatos de identificação em até sete semanas. Nesse sentido, a análise do esgoto se mostra útil na identificação de pessoas contaminadas em áreas específicas, possibilitando adoção de medidas de forma precoce no início de um surto. Além disso, é possível identificar variações expressivas entre áreas diferentes na mesma região, permitindo intervenções localizadas. Restringindo a aplicação à Covid-19, a ferramenta também pode auxiliar na identificação de pontos críticos, no direcionamento de ações de testagem, e até no acompanhamento dos efeitos da vacinação (CEDAE et al., 2021b).

\subsection{Aplicação do monitoramento de efluentes na cidade de Niterói}

Figura 2 - Pontos de coleta de amostras de esgoto

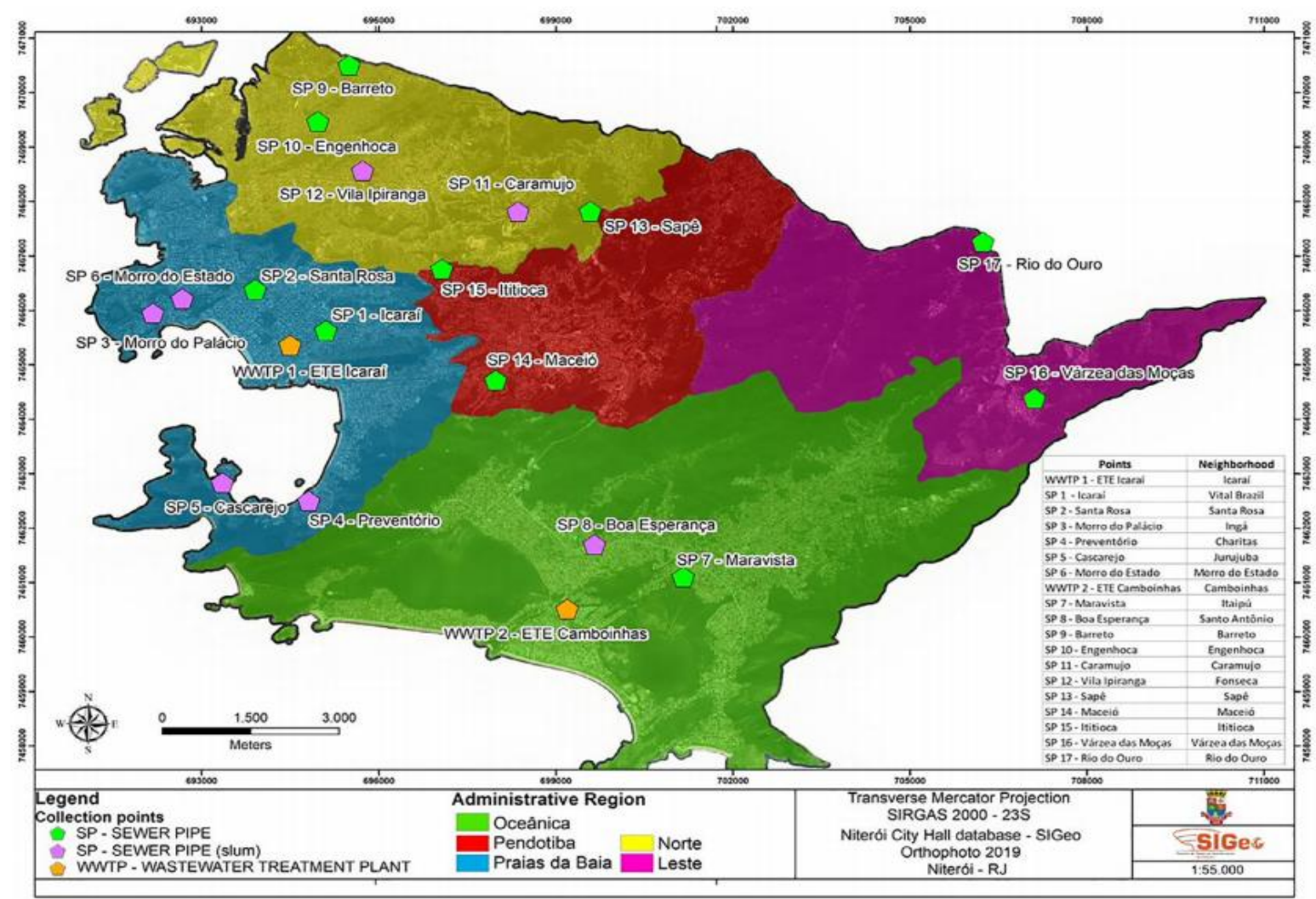

Fonte: Prado et al. (2021)

Também na região metropolitana do Rio de Janeiro, um trabalho de monitoramento da concentração do vírus SARS-COV-2 na rede coletora de esgoto da cidade de Niterói, foi conduzido pela Prefeitura da cidade (com o envolvimento multidisciplinar de algumas secretarias) e contou com a parceria da empresa concessionária de água e esgoto, Águas de Niterói, e da Fundação Oswaldo Cruz - Fiocruz (PRADO et al., 2021). Ainda de acordo com o autor, o critério utilizado para a escolha da área monitorada foi definido pela Secretaria Estadual de Saúde e levou em conta os seguintes aspectos: áreas com grande densidade populacional, áreas mais expostas à transmissão do vírus e áreas onde vivem populações economicamente vulneráveis e assistidas pelo sistema público de saúde. De acordo com este critério, foram definidos 19 pontos de coleta, como pode-se ver na Figura 2. 
Segundo Prado et al. (2021), o trabalho foi pioneiro no Brasil e, a partir dele, foi possível identificar áreas específicas com casos não reportados, sobretudo as mais vulneráveis, o que permitiu que testes e outros recursos fossem direcionados para estas regiões, o que não seria possível sem este monitoramento. E mesmo com o trabalho realizado numa cidade onde $94,5 \%$ da população tem seu esgoto coletado e tratado, o autor relata que a acurácia do método poderia ter sido melhor.

A parceria multidisciplinar entre governo municipal, operador de saneamento e instituto de pesquisa foi crucial para que a tomada de decisões e ações públicas fossem baseadas em evidências científicas. O autor ainda sugere que a experiência bem-sucedida poderá ser replicada em outras cidades do Brasil ou até em outros países que possuam interesse em usar o monitoramento ambiental do vírus no combate à pandemia.

\section{DISCUSSÃO}

O monitoramento da concentração do SARS-CoV-2 nas redes coletoras de esgoto, além de mostrar um retrato em tempo real da disseminação do vírus, pode servir de orientação para ações imediatas e medidas de controle desta e de futuras eventuais pandemias. Contudo, segundo Junior (2020), entre os fatores que classicamente governam a transmissibilidade de agentes patogênicos por via feco-oral está justamente a quantidade destes agentes nas excretas dos indivíduos contaminados. A respeito deste fator, ele comenta que os valores de referência sobre a concentração do vírus ativo ou fragmentos do seu RNA ainda não são completamente compreendidos e definidos por serem ainda pouco conhecidos. Contudo, há estudos dentro e fora do país que visam definir estes valores com o objetivo de atender a estratégia de monitoramento espaço-temporal da concentração do SARS-CoV-2 no sistema de esgotamento sanitário. A partir deste monitoramento, é possível apoiar ações de vigilância epidemiológica e tomadas de decisão para controle social, no caso de eventual sobrelevação da concentração do vírus indicando recrudescimento de sua transmissão.

Outro ponto a ser analisado, é a cinética de decaimento do SARS-CoV-2, que é considerada igual ou ainda mais acelerada que a de vírus não encapsulados, justamente pelo fato de seu envelopamento ser lipídico e de fácil degradação, sobretudo em meio com presença de água. Este pode ser um importante indicador para medição de possível contaminação via feco-oral (JUNIOR, 2020).

Como já comentado, apesar da viabilidade do novo coronavírus ter se mostrado pequena, estudos realizados na China mostram que, tanto o MERS-Cov quanto o SARS-CoV-1, sobrevivem por horas e até dias em diversos ambientes, inclusive no esgoto, indicando que o SARS-CoV-2 pode apresentar viabilidade similar nestes ambientes (YEO; YEO; KAUSHAL, 2020). De acordo com XIAO (2020), mais de $20 \%$ dos pacientes com RT-PCR negativo para o sistema respiratório, apresentaram resultado positivo quando o mesmo teste era realizado em suas fezes, o que demonstra que o vírus, não só atinge o trato intestinal, como também continua a ser transmitido por via fecal e pode ser levado pelos efluentes domésticos (residências e hospitais) para outros indivíduos, ainda que com baixa viabilidade.

\section{CONCLUSÕES}

Como visto nos dois estudos realizados na região metropolitana do Rio de Janeiro, é possível utilizar medidas relativamente simples de monitoramento da concentração viral no sistema de esgotamento sanitário como ferramenta de combate à epidemias, permitindo que as autoridades responsáveis pelas políticas públicas de saúde, possam agir com antecedência, principalmente, nas áreas social e 
economicamente mais vulneráveis. Tais políticas, se bem direcionadas, além de reduzir custos com tratamentos desnecessários, em última análise, podem evitar perda de vidas.

A despeito da acuracidade ainda não ideal, ambos os estudos demonstram e reforçam a importância da universalização do acesso ao saneamento básico, além do desenvolvimento de estudos na área de monitoramento de efluentes, a fim de garantir melhores resultados para suporte às ações de saúde pública.

\section{AGRADECIMENTOS}

Nosso agradecimento especial ao Professor Miguel Alvarenga Fernández y Fernández, presidente da ABESRio, pela disponibilidade, incentivo e apresentação do tema. Não poderíamos deixar de agradecer aos colegas do Mestrado em Engenharia Urbana da Escola Politécnica da UFRJ, pelas trocas essenciais ao longo do desenvolvimento deste trabalho.

\section{REFERÊNCIAS}

BRASIL. Lei № 14.026, de 15 de julho de 2020. Atualiza o marco legal do saneamento básico e altera a Lei no 9.984, de 17 de julho de 2000, para atribuir à Agência Nacional de Águas e Saneamento Básico (ANA) competência para editar normas de referência sobre o serviço de saneamento, a Lei ํㅜํ 10.768, de 19 de novembro de 2003, para alterar o nome e as atribuições do cargo de Especialista em Recursos Hídricos, a Lei n⿳⺈ 11.107, de 6 de abril de 2005, para vedar a prestação por contrato de programa dos serviços públicos de que trata o art. 175 da Constituição Federal, a Lei no 11.445, de 5 de janeiro de 2007, para aprimorar as condições estruturais do saneamento básico no País, a Lei no 12.305, de 2 de agosto de 2010, para tratar dos prazos para a disposição final ambientalmente adequada dos rejeitos, a Lei $\mathrm{n}^{\mathrm{o}}$ 13.089, de 12 de janeiro de 2015 (Estatuto da Metrópole), para estender seu âmbito de aplicação às microrregiões, e a Lei no 13.529 , de 4 de dezembro de 2017, para autorizar a União a participar de fundo com a finalidade exclusiva de financiar serviços técnicos especializados. Disponível em: <http://www.planalto.gov.br/ccivil_03/_ato20192022/2020/lei/114026.htm>. Acesso em: 16 maio 2021.

CEDAE et al. Monitora Corona. Rio de Janeiro, 2021. Monitoramento espaço-temporal da concentração de sars-cov-2 nos esgotos sanitários da RMRJ. Disponível em: <https://monitoracoronarj.com.br/>. Acesso em: 11 jun 2021.

Monitora Corona (Relatório Mensal 7). Rio de Janeiro, Abril de 2021. Disponível em: $<$ https://monitoracoronarj.com.br/wp-content/uploads/2021/05/Relatorio7_Abril.pdf >. Acesso em: 13 jun 2021.

COSTA, S. S.; HELLER, L.; BRANDAO, C. C. S.; COLOSIMO, E. A. Indicadores epidemiológicos aplicáveis a estudos sobre a associação entre saneamento e saúde de base municipal. Eng. Sanit. Ambient.(ABES). Rio de Janeiro, v.10, n.2, p.118-127, Junho de 2005. Disponível em: $<$ https://www.scielo.br/scielo.php?pid=S1413-41522005000200005\&script=sci_arttext\&tlng=pt $>$. Acesso em: 16 maio 2021.

HELLER, L. Saneamento e saúde. Brasília: OPAS/OMS, 1997. 97p.

HELLER, L.; MOTA, C. R.; GRECO, D. B. COVID-19 faecal-oral transmission: Are we asking the right questions?. The Science of the total environment, Online. Abril de 2020 . Disponível em: <https://www.ncbi.nlm.nih.gov/pmc/articles/PMC7182518/>. Acesso em: 15 maio 2021. 
INSTITUTO TRATA BRASIL. Trata Brasil: Saneamento e Saúde (Relatório). Rio de Janeiro: FGV/IBRE, CPS, 2007. Disponível em: <http://www.tratabrasil.org.br/datafiles/uploads/estudos/pesquisa1/texto.pdf >. Acesso em: 16 maio 2021.

Ranking do Saneamento 2021 (SNIS 2019). São Paulo, Março de 2021. Disponível em: <http://www.tratabrasil.com.br/images/estudos/Ranking_saneamento_2021/Press_release__Ranking_do_Saneamento_2021.pdf $>$. Acesso em: 06 jun 2021.

JUNIOR, I. V. Desenvolvimento do conhecimento sobre SARS-CoV-2 e Esgotos Sanitários. Departamento de Recursos Hídricos e Meio Ambiente (Escola Politécnica da Universidade Federal do Rio de Janeiro). Abril de 2020. Disponível em: <http://drhima.poli.ufrj.br/index.php/br/destaque/noticias/311-desenvolvimentodoconhecimento-sobre-sars-cov-2-e-esgotos-sanitarios>. Acesso em: 16 maio 2021.

OAB NACIONAL. Comissão Especial de Saneamento, Recursos Hídricos e Sustentabilidade. O Novo Marco Legal do Saneamento Básico (Cartilha). Brasília, 2020. Disponível em: $<$ http://www.agenersa.rj.gov.br/documentos/Legislacoes/cartilhasaneamento.pdf $>$. Acesso em: 14 maio 2021.

PRADO, T.; FUMIAN, T. M.; MANNARINO, C. F.; RESENDE, P. C.; MOTTA, F. C.; EPPINGHAUS, A. L. F.; VALE, V. H. C.; BRAZ, R, M. S.; ANDRADE, J. S. R.; MARANHÃO, A. G.; MIAGOSTOVICH, M. P. Wastewater-based epidemiology as a useful tool to track SARS-CoV-2 and support public health policies at municipal level in Brazil. Water Research. Online,v. 191, Março de 2021. Disponível em: <https://www.sciencedirect.com/science/article/pii/S0043135421000087>. Acesso em: 14 maio 2021.

RIBEIRO, J. W.; ROOK, J. M, S. Saneamento Básico e Sua Relação com o Meio Ambiente e a Saúde Pública. 2010. 36f. Trabalho de Conclusão de Curso (Especialização) - Faculdade de Engenharia. Universidade Federal de Juiz de Fora, Juiz de Fora, 2010. Disponível em: $<$ https://www.ufjf.br/analiseambiental/files/2009/11/TCC-SaneamentoeSa\%C3\%BAde.pdf $>$. Acesso em: 12 maio 2021.

ROSEN, G. Uma história da Saúde Pública. 2ª ed. São Paulo: Editora UNESP, 1994. 423p.

SECRETARIA DE ESTADO DE SAÚDE DE MINAS GERAIS. Monitoramento COVID esgotos. Belo Horizonte, 2021. Disponível em: <https://coronavirus.saude.mg.gov.br/transparencia/monitoramentocovid-esgotos>. Acesso em: 16 maio 2021.

TEIXEIRA, J. C.; GOMES, M. H. R.; SOUZA, J. A. Análise da Associação entre Saneamento e Saúde nos Estados Brasileiros: Estudo comparativo entre 2001 e 2006. Eng. Sanit. Ambient. (ABES). Rio de Janeiro, v. 16, n. 2, p. 197-204, Junho de 2011. Disponível em: <http://www.scielo.br/pdf/esa/v16n2/v16n2a14.pdf>. Acesso em: 16 maio 2021.

Associação entre cobertura por serviços de saneamento e indicadores epidemiológicos nos países da América Latina: estudo com dados secundários. Revista Panamericana de Salud Pública. WashingtonUSA, v. 32, n. 6, p. 419-425, 2012. Disponível em: <https://www.scielosp.org/pdf/rpsp/2012.v32n6/419425/pt>. Acesso em: 16 maio 2021.

XIAO, F.; TANG, M., ZHENG, X., LIU, Y.; LI, X.; SHAN, H. Evidence for Gastrointestinal Infection of SARSCoV-2. Gastroenterology, Online, Vol. 158, No. 6., Maio 2020. Disponível em: <https://www.ncbi.nlm.nih.gov/pmc/articles/PMC7182518/>. Acesso em: 15 maio. 2021. 
YEO, C.; KUASHAL, S.; YEO, D. Enteric involvement of coronaviruses: is faecal-oraltransmission of SARSCoV-2 possible?. Tan Tock Seng, The Lancet, vol 5, Abril. 2020. Disponível em: https://www.sciencedirect.com/science/article/abs/pii/S004896972032163X. Acesso em: 16 maio 2021. 